\title{
The Cyclicality of Hires, Separations, and Job-to-Job Transitions
}

\begin{abstract}
Robert Shimer
This paper measures the job-finding, separation, and job-to-job transition rates in the United States from 1948 to 2004. The job-finding and job-to-job transition rates are strongly procyclical and the separation rate is nearly acyclical, especially since 1985 . The author develops a simple model in which unemployed workers search for jobs and employed workers search for better jobs. The model predicts that an increase in either the job-finding rate or the separation rate raises the job-to-job transition rate, which is qualitatively and quantitatively consistent with the available evidence. In contrast, if the job-finding rate were acyclical and the separation rate countercyclical, as is the conventional wisdom, the model predicts that the job-to-job transition rate would be counterfactually countercyclical.
\end{abstract}

Federal Reserve Bank of St. Louis Review, July/August 2005, 87(4), pp. 493-507.

measure the job-finding and separation rates in the United States from 1948 to 2004 and find that there are substantial fluctuations in the job-finding probabilitythe monthly probability that a typical unemployed worker finds a job—at business cycle frequencies, whereas the separation probabilitythe monthly probability that a typical employed worker becomes unemployed-is comparatively acyclical (Figure 1). This finding is particularly true in the past two decades, a period in which the separation probability has steadily declined despite two spikes in the unemployment rate.

I then put these measures of the job-finding and separation probabilities into a simple model of job-to-job transitions. I assume employed workers continuously search for better employment opportunities: They experience a measured job-to-job transition either when they find a better job or when they are forced to leave their previous job but manage to find a new one before they are counted as unemployed. I show that an increase in the job-finding rate or an increase in the separation rate raises the job-to-job transition rate. Therefore, when I feed the measured time series for the job-finding and separation rates into this simple model, I predict that the job-to-job transition rate should be procyclical (Figure 4). This is quantitatively consistent with two direct measures of the job-to-job transition rate (Figures 5 and 6). In contrast, if separations were countercyclical and the job-finding rate acyclical, the basic model would predict a countercyclical job-to-job transition rate.

My findings that the job-finding rate is strongly procyclical and the separation rate is nearly acyclical oppose the conventional wisdom that recessions are primarily characterized by a high separation rate. In their 1996 book, Davis, Haltiwanger, and Schuh, building on evidence developed by Davis and Haltiwanger (1990 and 1992), conclude that evidence from the U.S. manu-

Robert Shimer is a professor of economics at the University of Chicago and a research associate at the National Bureau of Economic Research. The author is grateful for comments from Fernando Alvarez, Gadi Barlevy, Francesco Belviso, Robert Hall, and Randall Wright and from seminar participants at the Bank of Italy, Bocconi University, the Federal Reserve Bank of Chicago, Harvard University, the Federal Reserve Bank of St. Louis, and the University of Texas-Austin on an earlier version of this paper. Some of the ideas in that version are now contained in Shimer (2005b). The current paper was supported by grants from the National Science Foundation and the Sloan Foundation.

(C) 2005, The Federal Reserve Bank of St. Louis. Articles may be reprinted, reproduced, published, distributed, displayed, and transmitted in their entirety if copyright notice, author name(s), and full citation are included. Abstracts, synopses, and other derivative works may be made only with prior written permission of the Federal Reserve Bank of St. Louis. 
facturing sector indicates that "job destruction rises dramatically during recessions, whereas job creation initially declines by a relatively modest amount" (p. 34). Blanchard and Diamond (1990, p. 87) reach a similar conclusion from their analysis of both worker and job flows: "The amplitude of fluctuations in the flow out of employment is larger than that of the flow into employment. This, in turn, implies a much larger amplitude of the underlying fluctuations in job destruction than of job creation." 1

The development of macroeconomic models of the labor market has been profoundly affected by the conventional wisdom, ${ }^{2}$ but a series of recent papers by Hall $(2004 ; 2005 a, b)$ and Shimer $(2005 a, b)$ examine a variety of new data sets and question the prevailing view. For example, Hall (2004) writes that, "in the modern U.S. economy, recessions are not times of unusual job loss. New data on separations show them to be remarkably constant from peak to trough. Bursts of job loss had some role in earlier recessions, but are still mostly a side issue for the reason just mentioneda burst is quickly reabsorbed because of high jobfinding rates."

Relative to this new empirical literature, this paper's main contribution is its focus on job-tojob transitions. Burdett (1978) developed the first model of search by both unemployed and employed workers, showing that an unemployed worker uses a reservation strategy, accepting any job whose quality exceeds a lower bound, while an employed worker takes any job that is better than his current one. Pissarides (1994) and Burdett and Mortensen (1998) placed on-the-job search models into an equilibrium framework. I am aware of three recent analyses of on-the-job search in the presence of economic fluctuations: Barlevy (2002), who emphasizes that a decrease in the job-to-job transition rate during recessions leaves workers in less-productive jobs; Kraus and Lubik

\footnotetext{
1 For some skeptical views on these stylized facts, see Boeri (1996) and Foote (1998).

2 An incomplete list of well-known papers that embrace the conventional wisdom includes Mortensen and Pissarides (1994), Caballero and Hammour (1994), Hall (1995), Ramey and Watson (1997), Cole and Rogerson (1999), den Haan, Ramey, and Watson, (2000), and Pries (2004).
}

(2004), who show that job-to-job transitions can give rise to vacancy chains (Akerlof, Rose, and Yellen, 1988), amplifying fluctuations in the vacancy-unemployment ratio; and Nagypál (2004a), who examines a firm's choice of whether to hire an employed or unemployed worker and shows that a preference for hiring employed workers can also generate large fluctuations in the vacancy-unemployment ratio.

The methodology in this paper closely follows Shimer (2005b). Both papers emphasize that time aggregation leads to an overstatement of the cyclicality of the separation rate and offer a correction. Shimer (2005b) compares the proposed measure of the job-finding and separation rates with alternatives in the literature: It argues that cyclical changes in the composition of the unemployed population do not drive fluctuations in the jobfinding and separation rates; and it shows that cyclical movements of workers in and out of the labor force are also unimportant. The present paper focuses on developing a simple model of job-to-job transitions. It provides several different measures of the job-to-job transition rate and shows that, if in fact the job-finding rate is procyclical and the separation rate is acyclical, the model can account quantitatively for the behavior of the job-to-job transition rate.

When possible, I use readily available aggregate data so comparable measures can easily be constructed for particular industries or groups of workers or for other countries. ${ }^{3}$ I show how data on unemployment duration constructed by the Bureau of Labor Statistics (BLS) from the Current Population Survey (CPS) can be used to measure both the job-finding and separation rates. On the other hand, measures of the job-to-job transition rate necessitate using the underlying microeconomic data.

The next section provides measures of the job-finding and separation rates, accounting carefully for time aggregation. The third section develops a simple model of job-to-job transitions and discusses the theoretical response to an innovation in the job-finding or separation rate. It then develops several measures of the job-to-job tran-

\footnotetext{
3 But I have constructed these measures only for the United States.
} 
sition rate and argues that all are strongly procyclical and quantitatively consistent with the predictions of the simple model.

\section{MEASURING THE JOB-FINDING AND SEPARATION RATES}

This section develops theoretical measures of the job-finding rate for unemployed workers, $f_{t}$, and the separation rate for employed workers, $s_{t}$, during period $t$ and uses publicly available data from the CPS to measure the two transition rates. The job-finding rate is strongly procyclical, whereas the separation rate is less cyclical and explains little of the overall fluctuations in employment and unemployment, particularly during the past two decades.

\section{Theory}

I make two critical assumptions in this section; see Shimer (2005b) for evidence that they are good approximations of reality. First, I ignore movements in and out of the labor force, so workers simply move back and forth between employment and unemployment, where the latter is defined as the state of active job search. Second, I assume that all unemployed workers find a job at rate $f_{t}$ and all employed workers lose a job at rate $s_{t}$ during period $t$. In particular, I ignore any heterogeneity or duration dependence that makes some unemployed workers more likely to find and some employed workers less likely to lose a job within the period.

I model a continuous time environment in which data are available only at discrete dates $t \in\{0,1,2, \ldots\}$. I refer to the interval $[t, t+1)$ as "period $t$ "; fix $t \in\{0,1,2, \ldots\}$ and let $\tau \in[0,1]$ denote the time elapsed since the previous measurement date; and let $e_{t+\tau}$ denote the number of employed workers at time $t+\tau, u_{t+\tau}$ the number of unemployed workers at time $t+\tau$, and $u_{t}^{s}(\tau)$ as "short-term unemployment," workers who are unemployed at time $t+\tau$ but were employed at some time $t^{\prime} \in[t, t+\tau]$. Note that $u_{t}^{s}(0)=0$ for all $t$. It is convenient to define $u_{t+1}^{s} \equiv u_{t}^{s}(1)$ as the total amount of short-term unemployment at the end of period $t$. Because I cannot observe within- period variation in the job-finding or separation rate using available data, I assume that these are constant within periods. Let $f_{t} \geq 0$ and $s_{t} \geq 0$ denote the rate at which an unemployed worker finds a job and an employed worker loses a job, respectively, during period $t \in\{0,1,2, \ldots\}$. Throughout this paper, I refer to $f_{t}$ and $s_{t}$ as the job-finding and separation rates, respectively, and to $F_{t} \equiv 1$ $-e^{-f_{t}} \in[0,1]$ and $S_{t} \equiv 1-e^{-s_{t}} \in[0,1]$ as the corresponding probabilities, respectively (i.e., $F_{t}$ is the probability that a worker who begins period $t$ unemployed finds at least one job during the period and similarly for $S_{t}$ ).

For $t \in\{0,1,2, \ldots\}$ and $\tau \in[0,1)$, unemployment and short-term unemployment evolve according to

$$
\dot{u}_{t+\tau}=e_{t+\tau} s_{t}-u_{t+\tau} f_{t}
$$

and

$$
\dot{u}_{t}^{s}(\tau)=e_{t+\tau} s_{t}-u_{t}^{s}(\tau) f_{t} .
$$

Unemployment increases when employed workers separate from their jobs and decreases when unemployed workers find jobs, whereas short-term unemployment increases when employed workers separate from their jobs and decreases when short-term unemployed workers find jobs. Eliminate $e_{t+\tau} s_{t}$ between these equations to get

$$
\dot{u}_{t+\tau}=\dot{u}_{t}^{s}(\tau)-\left(u_{t+\tau}-u_{t}^{s}(\tau)\right) f_{t},
$$

for $\tau \in[0,1)$. By construction, $u_{t}^{s}(0)=0$, so given an initial condition for $u_{t}$, this can be solved for $u_{t+1}$ and $u_{t+1}^{s} \equiv u_{t}^{s}(1)$ :

$$
u_{t+1}=\left(1-F_{t}\right) u_{t}+u_{t+1}^{s} .
$$

The number of unemployed workers at date $t+1$ is equal to the number of unemployed workers at date $t$ who do not find a job during the period (fraction $1-F_{t}=e^{-f_{t}}$ ) plus the $u_{t+1}^{s}$ short-term unemployed workers, those who are unemployed at date $t+1$ but held a job at some point during period $t$. Given measures of unemployment and short-term unemployment, it is straightforward to back-out the job-finding probability from equation (3)

By assumption, the labor force, $l_{t}=e_{t}+u_{t}$, is constant during period $t$. This enables me to solve 
the differential equations (1) forward to obtain an implicit expression for the separation rate:

$$
u_{t+1}=\frac{\left(1-e^{-f_{t}-s_{t}}\right) l_{t} s_{t}}{f_{t}+s_{t}}+e^{-f_{t}-s_{t}} u_{t} .
$$

Because $l_{t}>u_{t}$, the right-hand side of this expression is increasing in $s_{t}$. Given the job-finding rate from equation (3) and data on unemployment and employment, equation (4) uniquely defines the separation rate, $s_{t} \cdot{ }^{4}$

To understand equation (4), note first that if unemployment is constant during period $t$, this reduces to a familiar formula, $u_{t} / l_{t}=s_{t} /\left(s_{t}+f_{t}\right)$, so the unemployment rate is determined by the ratio of the separation rate to the job-finding rate. Out of steady state, it helps to compare equation (4) with a discrete time model where there is no possibility of both finding and losing a job within a period. In this case,

$$
u_{t+1}=S_{t} e_{t}+\left(1-F_{t}\right) u_{t} .
$$

A fraction $S_{t}$ of employed workers lose their job and a fraction $F_{t}$ of unemployed workers find a job during period $t$, determining the unemployment rate at the start of period $t+1$. When the time period is sufficiently short, equation (4) converges to this simple expression. But with longer time periods, equation (4) allows workers to lose a job and find a new one, or vice versa, within the period. The distinction is quantitatively important for measuring both the level and cyclicality of the separation rate. When equation (3) indicates that the job-finding rate is high, a worker who loses her job is more likely to find a new one without experiencing a measured spell of unemployment. These separations are counted in equation (4) but missed in equation (5), so the latter formula yields an artificially negative correlation between the job-finding and separation rates-that is, a time aggregation bias.

\footnotetext{
4 A previous version of this paper proposed measuring the separation rate as $u_{t+1}^{s} f_{t} / e_{t}\left(1-e^{-f_{t}}\right)$, because a fraction $\left(1-e^{-f_{t}}\right) / f_{t}$ of the workers who lose their job during the period are still unemployed at the next measurement date. This is virtually identical to the measure of $s_{t}$ that I now use.
}

\section{Measurement}

Since 1948, the BLS has published monthly data on employment, unemployment, and unemployment duration based on the CPS. The measures of the number of employed and unemployed workers are standard, and I use these to quantify $e_{t}$ and $u_{t}$. The survey also asks unemployed workers how long they have been unemployed, and the BLS tabulates the number of unemployed workers with zero to four weeks' duration. With an adjustment for the CPS redesign in January 1994, discussed in the appendix, I use this as my measure of short-term unemployment, $u_{t}^{s}{ }^{5}$

Figure 1 shows the time series for the jobfinding probability, $F_{t}=1-e^{-f_{t}}$, and separation probability, $S_{t}=1-e^{-s_{t}}$, constructed according to equations (3) and (4) from 1948 to 2004. Several facts stand out. First, the job-finding probability is high, averaging 46 percentage points over the postwar period. Second, the job-finding probability is variable, falling by about 40 log points from peak to trough during recent decades. Third, the separation probability averaged 3.5 percentage points during the same period and was somewhat less volatile, particularly in recent years.

To examine the cyclicality of the job-finding and separation rates, recall that if unemployment is constant, $u_{t}=u_{t+1}$, equation (4) implies that the unemployment rate is $u_{t} / l_{t}=s_{t} /\left(s_{t}+f_{t}\right)$. In fact, this is a very good approximation. In monthly data, the correlation between the period $t$ "steady-state unemployment rate," $s_{t} /\left(s_{t}+f_{t}\right)$, and the end-ofperiod actual unemployment rate, $u_{t+1} / l_{t+1}$, is almost 0.99; so, the current job-finding and separation rates determine future unemployment rates. I use this strong relationship to distinguish between the importance of fluctuations in the job-finding and separation rates for determining fluctuations in unemployment. Let $\bar{f}$ and $\bar{s}$ denote the average values of $f_{t}$ and $s_{t}$ during the sample period and compute $\bar{s} /\left(\bar{s}+f_{t}\right)$ and $s_{t} /\left(s_{t}+\bar{f}\right)$ as measures of the contributions of fluctuations in the job-finding and separation rates to overall fluctuations in the unemployment rate.

\footnotetext{
5 These data can be downloaded from the BLS web site (www.bls.gov) or from the Federal Reserve Economic Database (FRED ${ }^{\circledR} \mathrm{II}$ ) of the Federal Reserve Bank of St. Louis:
} http://research.stlouisfed.org/fred2/. 


\section{Figure 1}

\section{Job-Finding and Separation Probabilities}

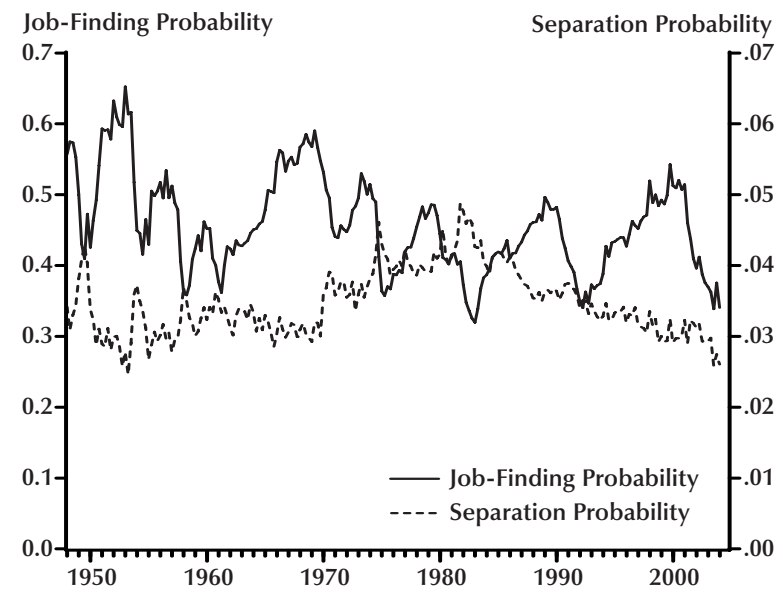

NOTE: Data, quarterly averages of monthly data, are from 1948:Q1-2004:Q1. The job-finding probability $F_{t}=1-\mathrm{e}^{-f_{t}}$ is constructed from unemployment and short-term unemployment according to equation (3). The separation probability $S_{t}=1-\mathrm{e}^{-S_{t}}$ is constructed from employment, unemployment, and the job-finding rate according to equation (4). Employment, unemployment, and short-term unemployment data are constructed by the BLS from the CPS and are seasonally adjusted.

The top panel in Figure 2 shows that a decline in the job-finding rate, $f_{t}$, contributed to every increase in the unemployment rate during the postwar period. The bottom panel shows that, from 1948 to 1985, the separation rate tended to move with the unemployment rate, although it rarely explained more than half the fluctuations in unemployment. In the past two decades, however, the separation rate has varied little over the business cycle. One way to quantify this is to look at the comovement of the detrended data. ${ }^{6}$ Over the entire postwar period, the correlation between the cyclical components of $u_{t+1} / l_{t+1}$ and $\bar{s} /\left(\bar{s}+f_{t}\right)$ is 0.96 , whereas the correlation between $u_{t+1} / l_{t+1}$ and $s_{t} /\left(s_{t}+\bar{f}\right)$ is 0.71 . The latter correlation has

6 I time-aggregate the underlying monthly data to get quarterly averages, removing substantial low-frequency fluctuations that likely reflect measurement error in the CPS. I then detrend the quarterly data using an HP filter with smoothing parameter $10^{5}$. This is a much lower-frequency filter than is commonly used in business cycle analyses of quarterly data. A standard filter seems to remove much of the cyclical volatility in the variable of interest.

\section{Figure 2}

Contribution of Fluctuations in the JobFinding and Separation Rates to Fluctuations in the Unemployment Rate
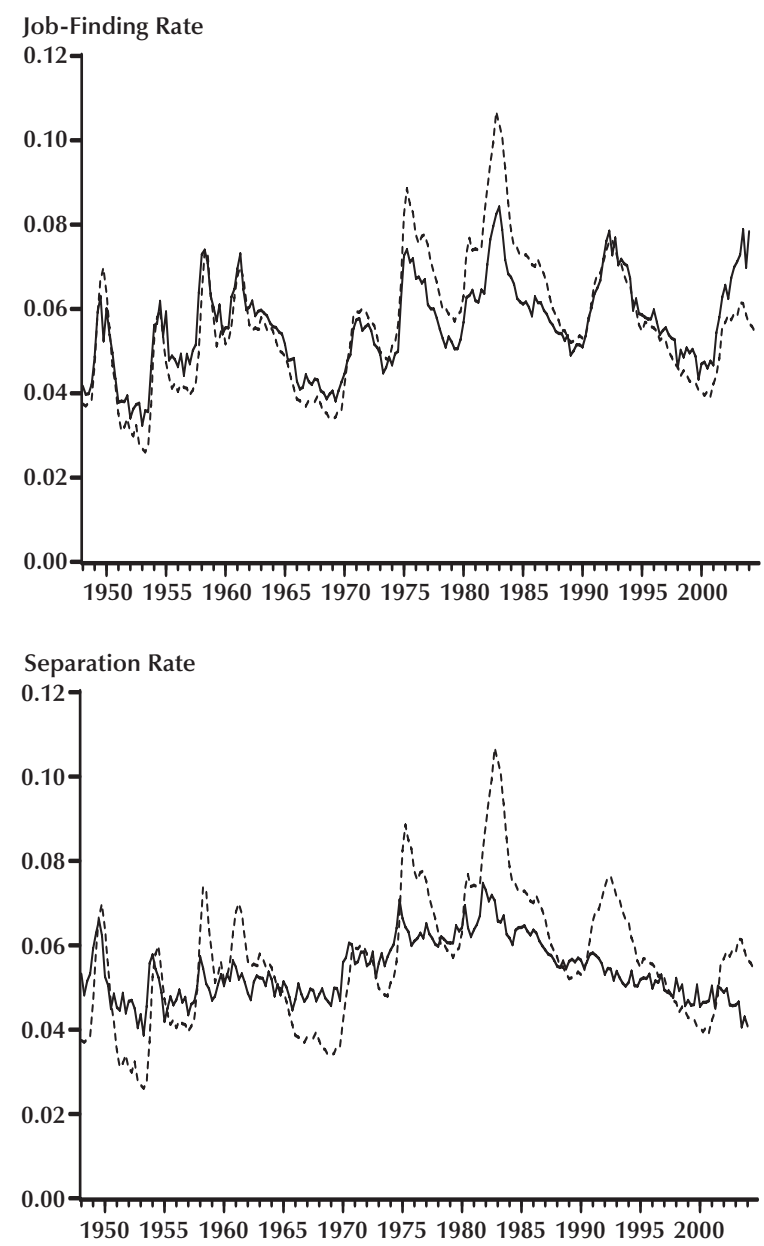

NOTE: Data, quarterly averages of monthly data, are from 1948:Q1-2004:Q1. The job-finding rate, $f_{t}$, is constructed from unemployment and short-term unemployment according to equation (3). The separation rate $s_{t}$ is constructed from employment, unemployment, and the job-finding rate according to equation (4). The top panel shows $\bar{s} /\left(\bar{s}+f_{t}\right)$ and the bottom panel shows $s_{t} /\left(s_{t}+f\right)$ as a solid line, with the unemployment rate graphed as a dashed line for comparison in each panel. Employment, unemployment, and short-term unemployment data are constructed by the BLS from the CPS and are seasonally adjusted. 
fallen to 0.20 since 1986. Moreover, $\bar{s} /\left(\bar{s}+f_{t}\right)$ is relatively volatile, with a cyclical standard deviation equal to 0.99 times that of $u_{t+1} / l_{t+1}$. The relative standard deviation of $s_{t} /\left(s_{t}+f\right)$ is just 0.28 .

\section{JOB-TO-JOB TRANSITIONS}

I now extend the basic model of transitions between employment and unemployment to allow employed workers to search for better jobs. I show analytically that a permanent increase in the jobfinding rate or in the separation rate raises the job-to-job transition rate. I also show numerically that a transitory increase has a similar effect. This implies that if the results described in the previous section are correct-that the job-finding rate is strongly procyclical and the separation rate is only weakly countercyclical-the job-to-job transition rate should be procyclical in the United States. I then confirm this prediction, both qualitatively and quantitatively, using a variety of data sources.

\section{Theory}

As before, assume that unemployed workers find a job at rate $f_{t}$ during month $t$ and employed workers lose their job at rate $s_{t}$. In addition, employed workers find an alternative job at rate $f_{t}^{e}$. To explain why workers switch jobs, I assume jobs are of different "quality," $y$, an index summarizing all of the job's pecuniary and nonpecuniary aspects. An unemployed worker accepts any job, ${ }^{7}$ whereas an employed worker accepts a new job only if its quality $y^{\prime}$ exceeds the previous job's quality, $y$. The critical assumption is that when a worker finds a job, the quality is drawn from a time-invariant continuous distribution, $Z(y)$, with support $[0, \bar{y}]$. This gives a simple model of jobto-job transitions in which workers switch jobs whenever they have an opportunity to improve their job quality.

To compute the theoretical job-to-job transition rate, it is necessary to keep track of the distribution of employed workers across job qualities. Let

7 Burdett (1978) shows that an unemployed worker's acceptance threshold will generally depend on labor market conditions. To keep the analysis simple, I ignore that possibility here.
$\tilde{G}_{t+\tau}(y)$ denote the fraction of employed workers whose job quality is less than $y$ at date $t+\tau$. Then $\tilde{G}_{t+\tau}(y) e_{t+\tau}$ is the total number of employed workers in jobs worse than $y$. For any $t+\tau$, this evolves according to

$$
\begin{aligned}
& \frac{d \tilde{G}_{t+\tau}(y) e_{t+\tau}}{d \tau} \\
& =u_{t+\tau} f_{t+\tau} Z(y)-\tilde{G}_{t+\tau}(y) e_{t+\tau}\left(s_{t+\tau}+f_{t+\tau}^{e}(1-Z(y))\right) .
\end{aligned}
$$

It increases when the $u_{t+\tau}$ unemployed workers find a job, at rate $f_{t+\tau}$, and the job has quality below $y$. It decreases when one of the $\tilde{G}_{t+\tau}(y) e_{t+\tau}$ workers employed in a job with quality below $y$ either suffers a separation (rate $s_{t+\tau}$ ) or finds a new job with quality above $y\left(\right.$ rate $\left.f_{t+\tau}^{e}(1-Z(y))\right)$. Because employment increases when unemployed workers find jobs and decreases when employed workers lose jobs, $\dot{e}_{t+\tau}=u_{t+\tau} f_{t+\tau}-e_{t+\tau} s_{t+\tau}$, the previous equation may be rewritten as

(6)

$$
\begin{aligned}
& \dot{\tilde{G}}_{t+\tau}(y)= \\
& \frac{u_{t+\tau} f_{t+\tau}}{e_{t+\tau}}\left(Z(y)-\tilde{G}_{t+\tau}(y)\right)-\tilde{G}_{t+\tau}(y) f_{t+\tau}^{e}(1-Z(y)) .
\end{aligned}
$$

I will say that a voluntary job-to-job transition occurs when a worker in a job with quality $y$ finds a better job, giving an instantaneous flow,

$$
\begin{aligned}
j_{t+\tau}^{v} & =f_{t+\tau}^{e} e_{t+\tau} \int_{0}^{\bar{y}}(1-Z(y)) \tilde{G}_{t+\tau}^{\prime}(y) d y \\
& =f_{t+\tau}^{e} e_{t+\tau} \int_{0}^{\bar{y}} \tilde{G}_{t+\tau}(y) Z^{\prime}(y) d y,
\end{aligned}
$$

where the second equality uses integration by parts. The total number of voluntary job changers during period $t$ is

$$
J_{t}^{v}=\int_{0}^{1} j_{t+\tau}^{v} d \tau
$$

The main difficulty in measuring $J_{t}^{v}$ using this equation is that the quality distribution, $Z$, is unobservable. Fortunately, this is unimportant. Rather than indexing a job opportunity by its quality, $y$, drawn from the distribution, $Z$, I represent it by its percentile in the quality distribution, $z$, which by definition is distributed uniformly on $[0,1]$. In addition, I define $G_{t}(Z(y)) \equiv$ $\tilde{G}_{t}(y)$ for all $y$. Then for $t \in\{0,1,2, \ldots\}$ and $\tau \in[0,1)$, the distribution of workers' normalized quality 
and the voluntary job-to-job transition rate satisfy

(9) $\dot{G}_{t+\tau}(z)=\frac{u_{t+\tau} f_{t}}{e_{t+\tau}}\left(z-G_{t+\tau}(z)\right)-G_{t+\tau}(z) f_{t}^{e}(1-z)$

$$
J_{t}^{v}=f_{t}^{e} \int_{0}^{1} e_{t+\tau}\left(\int_{0}^{1} G_{t+\tau}(z) d z\right) d \tau,
$$

where I use the standard assumption that the jobfinding rates, $f_{t+\tau}$ and $f_{t+\tau}^{e}$, are constant during period $t$ to simplify these expressions.

Given an initial guess at the distribution of $G$ and data on unemployment, $u_{t}$, employment, $e_{t}$, and job-finding rates, $f_{t}$ and $f_{t}^{e}$, it is possible to compute future distributions using equation (9). More precisely, I start each period $t$ with initial values for $u_{t}$ and $e_{t}$ (measured by the BLS from the CPS) and $G_{t}(z)$ (computed in the previous period). Second, I solve (1) to compute $u_{t+\tau}$ and $e_{t+\tau} \equiv u_{t}+e_{t}-u_{t+\tau}, \tau \in[0,1)$. Third, I use equation (9) to compute $G_{t+\tau}(z), \tau \in[0,1)$, on a grid of points $z \in\{0,0.01,0.02, \ldots, 1\}$. This computation has two purposes: $G_{t+1}(z)$ serves as initial condition in the next period, and I can approximate the entire function $G_{t+\tau}(z)$ with a cubic spline, calculating $\int_{0}^{1} G_{t+\tau}(z) d z$ at times $\tau \in\{0,0.1,0.2, \ldots, 1\}$. Again, using a cubic spline approximation, now along the time dimension, I can finally evaluate equation (10) to yield $J_{t}^{v}$.

Time aggregation introduces a second type of job-to-job transition, one that occurs when a worker separates from her job but manages to find a new one before the next survey date. At time $t+\tau$, there are $u_{t}^{s}(\tau)$ workers who have separated from their jobs since the previous survey date, each of whom finds a job at rate $f_{t}$. This means the measured "involuntary" job-to-job transition rate between months $t$ and $t+1$ is

$$
J_{t}^{i}=f_{t} \int_{0}^{1} u_{t}^{s}(\tau) d \tau .
$$

This rate is easy to measure using the variables constructed in the second section, "Measuring the Job-Finding and Separation Rates."

Finally, the total number of workers who switch employers during the preceding month is $J_{t}=J_{t}^{v}+J_{t}^{i}$ :

(12) $J_{t}=f_{t}^{e} \int_{0}^{1} e_{t+\tau}\left(\int_{0}^{1} G_{t+\tau}(z) d z\right) d \tau+f_{t} \int_{0}^{1} u_{t}^{s}(\tau) d \tau$.
The job-to-job transition rate is the ratio of this to employment, $J_{t} / e_{t}$.

\section{Comparative Statics and Impulse Response}

In steady state, it is possible to solve equation (9) for $G(z)$, simplifying with the steady-state unemployment condition $u f=e s$ :

$$
G(z)=\frac{s z}{s+f^{e}(1-z)} .
$$

I substitute this into (10) to obtain the voluntary job-to-job transition rate:

$$
\frac{J^{v}}{e}=s\left(\frac{f^{e}+s}{f^{e}} \log \left(\frac{f^{e}+s}{f^{e}}\right)-1\right) .
$$

This rate is independent of the job-finding rate for unemployed workers, $f$, but is increasing in both the job-finding rate for employed workers, $f^{e}$, and in the separation rate, $s$. That the voluntary job-to-job transition rate is increasing in the job-finding rate for employed workers is intuitive. To understand the comparative static with respect to the separation rate, consider an extreme economy without separations. Eventually all workers will find the best possible job, $z=1$, and there will be no more job-to-job transitions. A higher separation rate pushes more workers down the job ladder, which raises the possibility of voluntary job-to-job transitions.

Still in steady state, equation (2) implies $\dot{u}_{t}^{s}(\tau)=e_{t} s_{t}-u_{t}^{s}(\tau) f_{t}$. I use the initial condition $u_{t}^{s}(0)=0$ and integrate over $\tau \in[0,1]$ to get an analytic expression for $\int_{0}^{1} u_{t}^{s}(\tau) d \tau$, which can be substituted into equation (11). This calculation implies that the steady-state involuntary job-tojob transition rate is

$$
\frac{J^{i}}{e}=s\left(1-\frac{1-e^{-f}}{f}\right) .
$$

This rate is unaffected by the job-finding rate for employed workers but is increasing in both the separation rate and the job-finding rate for unemployed workers. A higher separation rate places more workers in a position to undertake an involuntary job-to-job transition, whereas a higher job-finding rate permits more of these 


\section{Figure 3}

\section{Theoretical Response of Unemployment and the Job-to-Job Transition Rate to a Shock to the Job-Finding or Separation Rate}
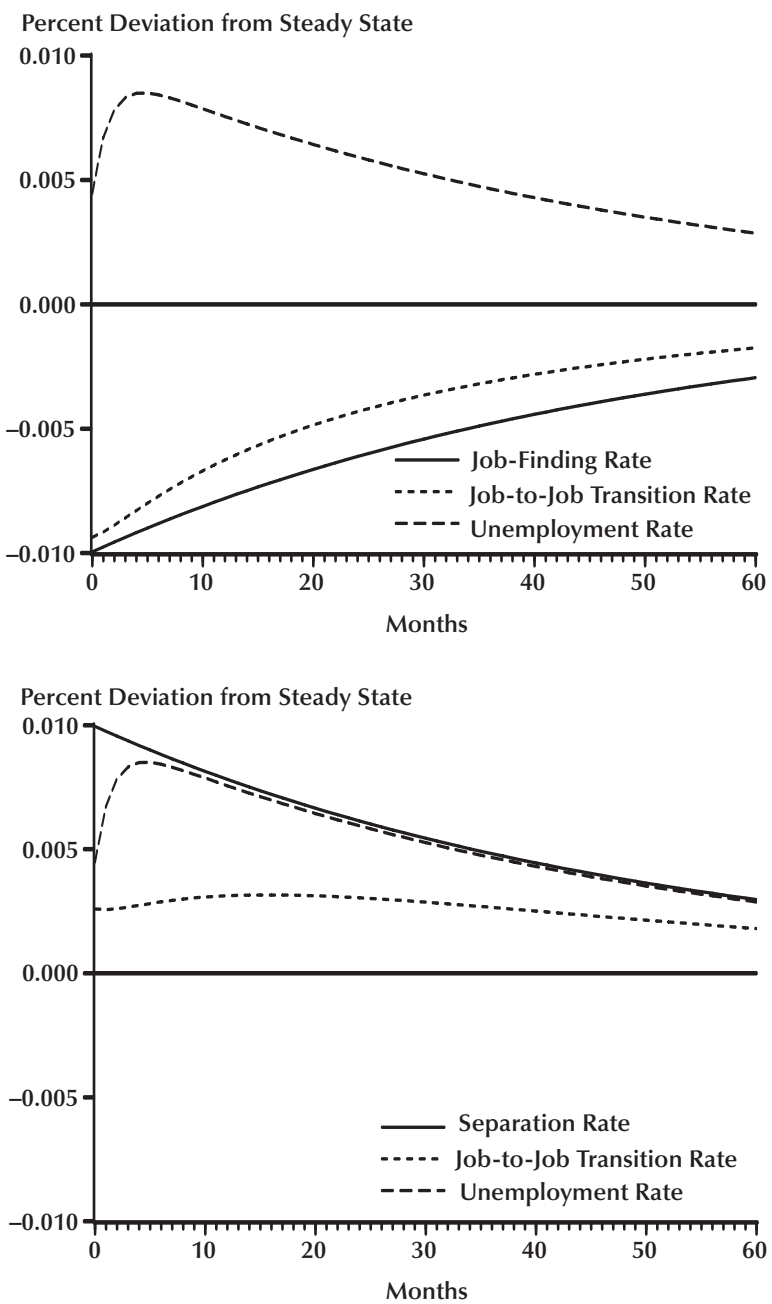

workers to do so. In summary, the steady-state job-to-job transition rate,

$$
\frac{J}{e}=s\left(\frac{f^{e}+s}{f^{e}} \log \left(\frac{f^{e}+s}{f^{e}}\right)-\frac{1-e^{-f}}{f}\right),
$$

is increasing in the separation rate and both jobfinding rates.

The behavior of the economy out of steady state is similar to that suggested by the comparative statics. An increase in the separation rate or a reduction in the job-finding rate both raise the unemployment rate, but their effects on the jobto-job transition rate are distinct. An increase in the separation rate initially raises the involuntary job-to-job transition rate as some displaced workers find their way back into a new job within the period. Additionally, higher separation rates in the recent past raise the voluntary job-to-job transition rate as previously displaced workers go through multiple jobs before finding a very good match. Thus, the job-to-job transition rate tends to increase and remain high following a transitory increase in the separation rate. In contrast, a decrease in the job-finding rate reduces both voluntary and involuntary job-to-job transitions because fewer employed or recently displaced workers find a worthwhile job opportunity within the period.

To quantify these effects, I consider an economy that is initially in steady state with a jobfinding rate of $f_{-1}=0.61$ and a separation rate of $s_{-1}=0.035$, equal to the average U.S. monthly transition rates from 1948 to 2004 . I also set $f_{-1}^{e}=$ $0.15 f_{-1}$, a reasonable value for the relative efficiency of on-the-job search, as I will discuss further. Assume that the parameters of the economy have been constant for a while, so the unemployment rate is at its steady-state value, $u_{-1}=0.054$, and the distribution of employed workers across job quality is also in steady state. Consider two experiments in this model economy: a 1 percent increase in the separation rate that reverts to steady state at 2 percent per month, so $s_{t}=0.03535 \times$ $0.98^{t}+0.35 \times\left(1-0.98^{t}\right)$ for $t \in\{0,1,2, \ldots\}$, with $f_{t}=0.61$ for all $t$; or a 1 percent, mean-reverting decrease in the job-finding rate, so $f_{t}=0.60396 \times$ $0.98^{t}+0.61 \times\left(1-0.98^{t}\right)$ for $t \in\{0,1,2, \ldots\}$, with $s_{t}=0.035$ for all $t$. In both cases, I let $f_{t}^{e}=0.15 f_{t}$ for all $t$.

Figure 3 shows the behavior of unemployment and the job-to-job transition rate in response to these shocks. By construction, unemployment behaves identically, but the cyclicality of the job-to-job transition rate depends on the nature of the shock. The top panel shows that the jobto-job transition rate closely tracks a transitory decrease in the job-finding rate; the bottom panel shows that the job-to-job transition rate fluctuates 
less and is more persistent in response to a transitory increase in the separation rate. Most important, if cyclical volatility in unemployment is primarily due to fluctuations in the job-finding rate, the model predicts that the job-to-job transition rate should be procyclical (i.e., negatively correlated with unemployment). If it is primarily due to fluctuations in the separation rate, the job-to-job transition rate should be countercyclical (positively correlated with unemployment).

\section{Measurement}

To test this theory, I compare the job-to-job transition rate predicted by this simple model with direct evidence on the empirical transition rate. Because the job-finding rate is strongly procyclical and the separation rate is weakly countercyclical, it is not obvious a priori whether the theory predicts a procyclical or countercyclical job-to-job transition rate. To answer this, I feed into the model monthly employment and unemployment measures from the CPS $\left(e_{t}\right.$ and $u_{t}$, respectively); the monthly job-finding rate, $f_{t}$, computed from equation (3); and the monthly separation rate, $s_{t}$, computed from equation (4). I also fix $f_{t}^{e}=a f_{t}$ and examine three values for the relative efficiency of on-the-job search, $a \in\{0.50,0.15,0.05\}$. Figure 4 shows the resulting series for the job-to-job transition rate, constructed according to equation (12), with the unemployment rate plotted for comparison. The theoretical job-to-job transition rate is strongly negatively correlated with unemployment, regardless of the value of $a$. After removing a low-frequency trend, the correlation between the job-to-job transition rate and the unemployment rate ranges from -0.89 with $a=0.05$ to -0.80 with $a=0.50$, and the relative standard deviation lies between 0.65 with $a=0.05$ and 0.53 with $a=0.50$. For example, the theory suggests that the job-to-job transition rate should have fallen by between 0.31 and $0.44 \log$ points during 2001 and 2002, a period during which the job-finding rate fell and the separation rate remained roughly constant.

There is no ideal empirical measure of the job-to-job transition rate to test this prediction, so I rely on three imperfect measures. The first

\section{Figure 4}

\section{Theoretical Job-to-Job Transition Rate, Constructed According to Equation (12)}

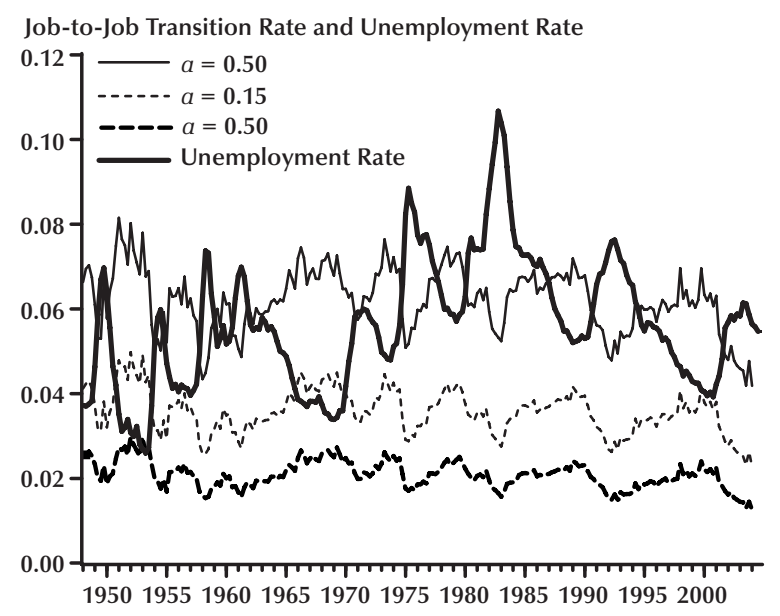

NOTE: Data, quarterly averages of monthly data, are from 1948:Q1-2004:Q1. Employment, unemployment, and shortterm unemployment are measured by the BLS from the CPS, and the remaining variables are constructed as described in the paper, with $f_{t}^{\mathrm{e}}=a f_{t}$. The unemployment rate is shown for comparison.

methodology, pioneered by Fallick and Fleischman (2004) and recently employed by Nagypál (2004b) examines a question in the public use microeconomic data from the monthly CPS. ${ }^{8}$ Since the switch to dependent interviewing in 1994, the survey has asked the following question of respondents who continue to be employed in consecutive months: "Last month, it was reported that you worked for $x$. Do you still work for $x$ (at your main job)?" I use the fraction of employed workers who answer this question negatively, weighted by the CPS final weights, to compute the empirical job-to-job transition rate. A potential shortcoming of this method is that no individual is permitted to experience multiple job-to-job movements within a month, a possibility that is nonnegligible when the job-finding rate is high. More importantly, because the relevant question has been asked only since 1994 , it is possible to

8 These data can be downloaded from the NBER web site: www.nber.org/data/cps_basic.html. 


\section{Figure 5}

\section{Empirical and Theoretical Job-to-Job Transition Rate}

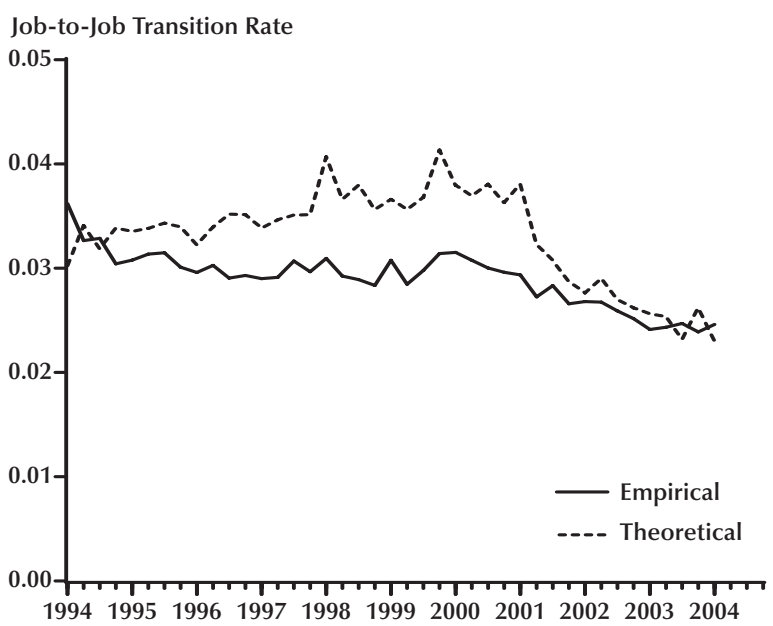

NOTE: Data, quarterly averages of monthly data, are from 1994:Q1-2004:Q1. The empirical job-to-job transition rate is computed from public use CPS micro data as the fraction of employed workers who have a "new employer" rather than the "same employer as last month." The theoretical job-to-job transition rate is computed using equation (12) with $a=0.15$.

analyze only one cyclical downturn using this measure.

With these caveats, Figure 5 shows the empirical behavior of this measure of the job-tojob transition rate, with the prediction of the theoretical model ( $a=0.15$ ) included for comparison. The fact that the levels are approximately correct is due to a judicious choice of the relative effectiveness of on-the-job search $a$. But the underlying data on job-finding and separation rates drive the fluctuations in the theoretical series. Although the theory predicts a moderate increase in the job-to-job transition rate during the second half of the 1990s while the data show little trend, the model is reasonably good at explaining the decline in job-to-job transitions from 2001 to 2003.

Another measure of the job-to-job transition rate uses the public-use micro data in the March supplement to the CPS

(www.nber.org/data/cps.html). Since 1976, the March supplement has asked workers how many employers they had in the previous year. A coarse measure of the number of job-to-job transitions is $\sum_{i=1}^{\infty} n_{i}(i-1)$, where $n_{i}$ is the number of workers reporting $i$ employers. I multiply this by 52 and divide by the total number of weeks worked in the previous year to obtain the job-to-job transition rate per full year of work. Of course, many workers have a spell of unemployment in between employers, so this should be an upper bound on the jobto-job transition rate. To obtain a lower bound, I look only at people who reported working for 52 weeks. An intermediate estimate follows Blanchard and Diamond (1990) and examines a question about the number of spells of job search. I assume that a worker who reports $i$ employers and $j$ spells of job search had $\max \{i-j-1,0\}$ jobto-job transitions during the previous year.

The main advantage to this measure is that the necessary questions have been asked every year since $1976 .{ }^{9}$ But there are three significant disadvantages. The data are available only on an annual basis, a lower frequency than is ideal for business cycle analysis. The questions are retrospective, so respondents may forget some job-tojob transitions. And the number of job-to-job transitions is capped at three per year, which understates the true job-to-job transition rate. Figure 6 shows the upper, intermediate, and lower measures of the job-to-job transition rate based on March CPS data. The most striking finding is that even the upper bound lies significantly below the estimate using the monthly CPS (Figure 5). But despite this difference in the level, the March CPS data confirm that the job-to-job transition rate is procyclical. In fact, Figure 6 shows that the theoretical prediction of the job-to-job transition rate with a low value of the relative efficiency of on-the-job search $(a=0.05)$ closely tracks the upper-bound empirical estimate.

A final method of estimating the job-to-job transition rate comes from the Job Openings and Labor Turnover Survey (JOLTS; www.bls.gov/jlt). Since December 2000, this BLS survey has asked business establishments how many workers they have added to their payrolls during the previous

\footnotetext{
9 The question in the year- $t$ CPS asks about employers in year $t-1$, so I have data from 1975 to 2003.
} 


\section{Figure 6}

\section{Empirical and Theoretical Job-to-Job Transition Rate, 1975-2003}

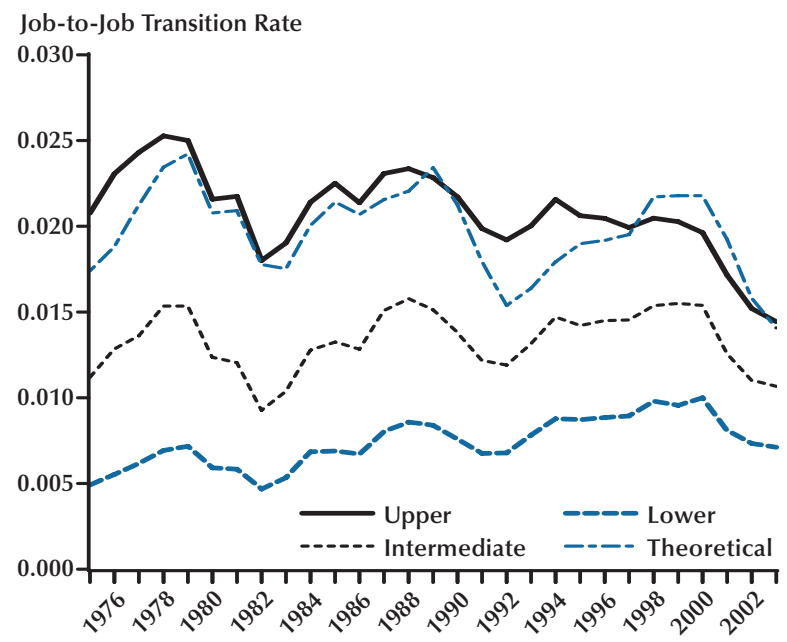

NOTE: The upper, intermediate, and lower empirical job-to-job transition rates are computed from the public use files of the March CPS, as described in the text. The theoretical job-to-job transition rate is computed using equation (12) with $a=0.05$.

month, how many workers left their payrolls, and whether those workers were laid off or quit. Figure 7 suggests that both new hires and separations fell as the United States labor market remained weak in 2002 and 2003. More tellingly, Figure 8 shows only a brief small spike in layoffs just after the terrorist attacks in September 2001, while the number of instances in which a worker quit her job fell steadily during this period. ${ }^{10}$ For present purposes, it is notable that both new hires and "quits" fell by approximately 0.6 percentage points between 2001 and 2003. This finding is most easily explained by a decline in voluntary job-to-job transitions of the same magnitude, which reduced both new hires and quits.

In summary, if downturns were periods with high separation rates and normal job-finding rates, the model described in this paper would predict

\footnotetext{
${ }^{10}$ Akerlof, Rose, and Yellen (1988) discuss an old BLS survey of turnover in manufacturing establishments. Their Figure 1 shows that quits were strongly procyclical, whereas their Figure 2 shows brief spikes in layoffs at the start of a downturn. Unfortunately, the BLS discontinued this survey in 1982.
}

\section{Figure 7}

\section{New Hires and Total Separations as a Percent of Employment}

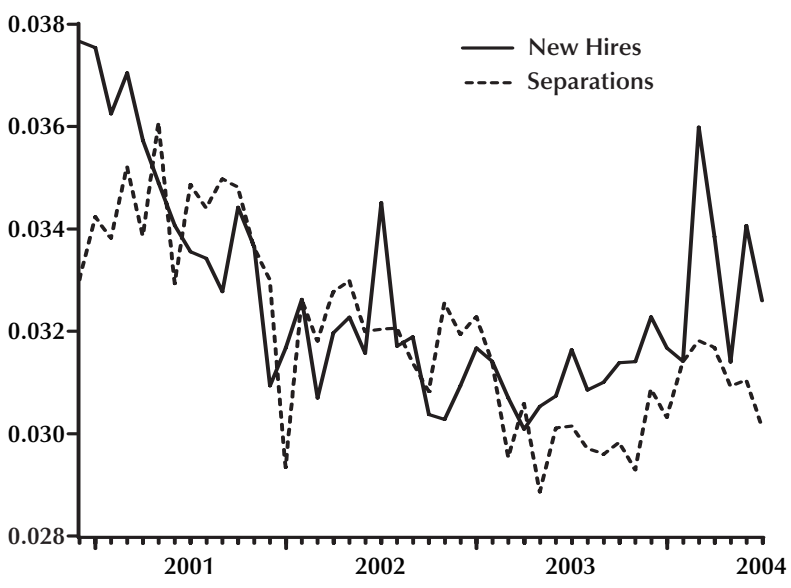

NOTE: Data are from December 2000 through July 2004 (seasonally adjusted) and are constructed by the BLS as part of the JOLTS program.

\section{Figure 8}

\section{Layoffs and Quits as a Percent of Employment}

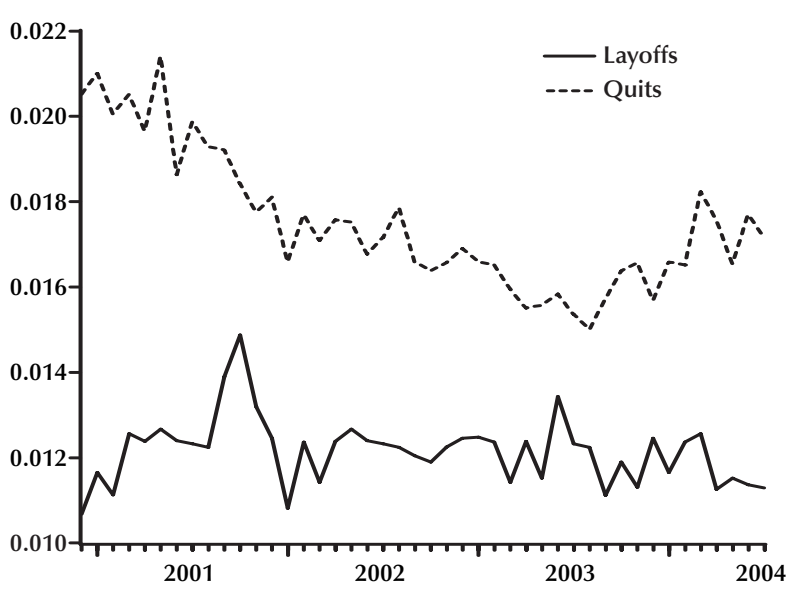

NOTE: Data are from December 2000 through July 2004 (seasonally adjusted) and are constructed by the BLS as part of the JOLTS program. 
an increase in job-to-job transitions during downturns, and in particular from 2001 to 2003 . This increase would occur both because of an increase in the number of workers who suffer a separation but manage to find a new job and because the increase in separations would reduce the age of matches and hence their quality, causing more voluntary job-to-job transitions. The finding that job-to-job transitions typically fall during downturns is consistent with the evidence that workers find it harder to obtain a job during downturns and do not experience a large increase in their separation rate.

\section{CONCLUSIONS}

This paper argues that business cycle fluctuations in unemployment are primarily a consequence of changes in the probability that an unemployed worker finds a job within a monththe job-finding probability. Changes in the separation rate do not explain any of the observed unemployment fluctuations during the past two decades. A simple model of on-the-job search suggests that in such an environment, job-to-job transitions should be procyclical, consistent with recent evidence from JOLTS and the monthly CPS and historical evidence from the March CPS. In contrast, if the job-finding rate were acyclical and the separation rate countercyclical, the simple model would predict that the job-to-job transition rate would be countercyclical.

The interesting follow-up question is why there are times when it is so hard to find a job. This paper does not provide an answer, but some recent research by Kraus and Lubik (2004) and Nagypál (2004b) suggests that job-to-job transitions may be an important element of the answer. ${ }^{11}$ Kraus and Lubik (2004) make two important assumptions. First, they assume that on-the-job search intensity is highly elastic, so a small change in labor market conditions leads to a large change in the amount of search by employed workers.

\footnotetext{
${ }^{11}$ Some other recent research that attempts to explain fluctuations in the job-finding rate focuses on wage rigidities arising either from social norms or asymmetric information. See Hall (2004), Kennan (2004\}, and Shimer and Wright (2004).
}

Second, they work in a multisector model in which the output of each sector is complementary to the production of a final consumption good. When an employed worker switches sectors, the marginal revenue product of labor in the originating sector increases, giving an incentive for firms in that sector to create new vacancies. This creates something analogous to a vacancy chain (Akerlof, Rose, and Yellen, 1988). In this environment, a small positive productivity shock induces much more search by employed workers. As those workers start to find jobs in more-productive sectors, the low-productivity sectors create additional job openings, which draw workers out of unemployment. This generates large fluctuations in the vacancy-unemployment ratio. Although this research appears promising, my analysis in this paper assumed that employed workers' search intensity is inelastic and generated approximately correct fluctuations in the job-to-job transition rate. This result suggests that if employed workers' search intensity is highly procyclical, the model will generate too-large fluctuations in the job-tojob transition rate.

Nagypál (2004b) also gives job-to-job transitions a prominent role in her analysis. She proposes that to understand the cyclicality of vacancies, one has to understand whether firms prefer to hire employed or unemployed workers. She argues that firms prefer employed workers because, when an employed worker is willing to take a job offer, this is a strong signal that the worker likes the job. In contrast, unemployed workers will accept any job but continue to search for a better one. If turnover is costly and a worker cannot be forced to bear the full cost of her decision to leave a job, firms will then prefer to hire employed workers. And because employed workers are a relatively large portion of the searching population during booms, this encourages firms to create vacancies. Whether or not either of these explanations is ultimately proved correct, it seems likely that a satisfactory model of the job-finding rate will explain why it is harder both for unemployed and employed workers to find jobs during downturns. 


\section{REFERENCES}

Abraham, Katharine G. and Shimer, Robert. "Changes in Unemployment Duration and Labor-Force Attachment," in Alan Krueger and Robert Solow, eds., The Roaring Nineties: Can Full Employment Be Sustained?" New York: Russell Sage Foundation and Century Foundation, 2001, pp. 367-420.

Akerlof, George A.; Rose, Andrew K. and Yellen, Janet L. "Job Switching and Job Satisfaction in the U.S. Labor Market." Brookings Papers on Economic Activity, 1988, (2), pp. 495-582.

Barlevy, Gadi. "The Sullying Effect of Recessions." Review of Economic Studies, January 2002, 69(1), pp. 65-96.

Blanchard, Olivier Jean and Diamond, Peter. "The Cyclical Behavior of the Gross Flows of U.S. Workers.” Brookings Papers on Economic Activity, 1990, (2), pp. 85-143.

Boeri, Tito. “Is Job Turnover Countercyclical?” Journal of Labor Economics, October 1996, 14(4), pp. 603-25.

Burdett, Kenneth. "A Theory of Employee Job Search and Quit Rates." American Economic Review, March 1978, 68(1), pp. 212-20.

Burdett, Kenneth and Mortensen, Dale T. "Wage Differentials, Employer Size, and Unemployment." International Economic Review, May 1998, 39(2), pp. 257-73.

Caballero, Ricardo J. and Hammour, Mohamad L. "The Cleansing Effect of Recessions." American Economic Review, December 1994, 84(5), pp. 1350-68.

Cole, Harold L. and Rogerson, Richard. "Can the Mortensen-Pissarides Matching Model Match the Business-Cycle Facts?" International Economic Review, November 1999, 40(4), pp. 933-59.

Davis, Steven J. and Haltiwanger, John. "Gross Job Creation and Destruction: Microeconomic Evidence and Macroeconomic Implications" in Olivier Jean Blanchard and Stanley Fischer, eds., NBER Macroeconomics Annual 1990. Cambridge, MA: MIT Press, 1990, pp. 123-68.
Davis, Steven J. and Haltiwanger, John C. "Gross Job Creation, Gross Job Destruction, and Employment Reallocation." Quarterly Journal of Economics, August 1992, 107(3), pp. 818-63.

Davis, Steven J.; Haltiwanger, John C. and Schuh, Scott. Job Creation and Destruction. Cambridge, MA: MIT Press, 1996.

den Haan, Wouter; Ramey, Garey and Watson, Joel. "Job Destruction and Propagation of Shocks." American Economic Review, June 2000, 90(3), pp. 482-98.

Fallick, Bruce and Fleischman, Charles. "Employerto-Employer Flows in the U.S. Labor Market: The Complete Picture of Gross Worker Flows." Finance and Economics Discussion Series Working Paper 2004-34, Board of Governors of the Federal Reserve System, 2004.

Foote, Christopher. "Trend Employment Growth and the Bunching of Job Creation and Destruction." Quarterly Economic Review, August 1998, 113(3), pp. 809-34.

Hall, Robert E. "Lost Jobs.” Brookings Papers on Economic Activity, 1995, (1), pp. 221-56.

Hall, Robert E. "The Labor Market Is Key To Understanding the Business Cycle.” Unpublished manuscript, Stanford University, September 23, 2004.

Hall, Robert E. "Employment Efficiency and Sticky Wages: Evidence from Flows in the Labor Market." Review of Economics and Statistics, 2005a (forthcoming).

Hall, Robert E. "Employment Fluctuations with Equilibrium Wage Stickiness." American Economic Review, 2005b, 95(1), pp. 50-65.

Kennan, John. "Private Information, Wage Bargaining and Employment Fluctuations." Unpublished manuscript, University of Wisconsin-Madison, April 2004.

Kraus, Michael and Lubik, Thomas. "On-the-Job Search and the Cyclical Dynamics of the Labor Market." Unpublished manuscript, University of Tilburg, 2004. 
Mortensen, Dale T. and Pissarides, Christopher A. "Job Creation and Job Destruction in the Theory of Unemployment." Review of Economic Studies, July 1994, 61(3), pp. 397-415.

Nagypál, Éva. “Amplification of Productivity Shocks: Why Vacancies Don't Like To Hire the Unemployed?” Unpublished manuscript, Northwestern University, 2004a.

Nagypál, Éva. "Worker Reallocation over the Business Cycle: The Importance of Job-to-Job Transitions.” Unpublished manuscript, Northwestern University, 2004b.

Pissarides, Christopher A. "Search Unemployment with On-the-Job Search." Review of Economic Studies, July 1994, 61(3), pp. 457-75.

Polivka, Anne E. and Miller, Stephen M. “The CPS after the Redesign," in John Haltiwanger, Marilyn Manser, and Robert Topel, eds., Labor Statistics Measurement Issues. Chicago: University of Chicago Press, pp. 249-89.

Pries, Michael J. "Persistence of Employment Fluctuations: A Model of Recurring Job Loss.” Review of Economic Studies, January 2004, 71(1), pp. 193-215.
Ramey, Garey and Watson, Joel. "Contractual Fragility, Job Destruction, and Business Cycles." Quarterly Economic Review, August 1997, 112(3), pp. 873-911.

Shimer, Robert. "The Cyclical Behavior of Equilibrium Unemployment and Vacancies.” American Economic Review, 2005a, 95(1), pp. 25-49.

Shimer, Robert. "Reassessing the Ins and Outs of Unemployment.” Unpublished manuscript, University of Chicago, 2005b.

Shimer, Robert and Wright, Randall. "Competitive Search Equilibrium with Asymmetric Information." Unpublished manuscript, University of Chicago, August 26, 2004.

Solon, Gary. "Effects of Rotation Group Bias on Estimation of Unemployment." Journal of Business and Economic Statistics, January 1986, 4(1), pp. 105-09.

\section{APPENDIX}

\section{MEASUREMENT OF SHORT-TERM UNEMPLOYMENT}

To measure short-term unemployment, I rely on workers' self-reported duration of an in-progress unemployment spell. Unfortunately, the CPS instrument was redesigned in January 1994, changing how the unemployment duration question was asked (Abraham and Shimer, 2001). ${ }^{12}$ Recall that the CPS is a rotating panel. Each household is in the CPS for four consecutive months (rotation groups 1 to 4), out for eight months, and then in again for four more months (rotation groups 5 to 8). This means that in any month, approximately three-quarters of the households in the survey were also interviewed in the previous month.

Until January 1994, unemployed workers in all eight rotation groups were asked how long they had been unemployed. But since then, the CPS has not asked a worker who is unemployed in consecutive months the duration of her unemployment spell in the second month. Instead, the BLS calculates unemployment duration in the second month as the sum of unemployment duration in the first month plus the intervening number of weeks. Thus, prior to 1994, the CPS measure of short-term unemployment

${ }^{12}$ See Polivka and Miller (1998) for a thorough analysis of the redesign of the CPS instrument. 
should capture the total number of unemployed workers who were employed at any point during the preceding month, whereas after the redesign, short-term unemployment captures only workers who transition from employment at one survey date to unemployment at the next survey date. ${ }^{13}$

There is no theoretical reason to prefer one measure to the other, because they simply measure different objects. But the method I use to measure the job-finding and separation rates in the second section of this paper ("Measuring the Job-Finding and Separation Rates") relies on the pre-1994 measure of short-term unemployment. In any case, the goal of this paper is to obtain a consistent time series for the job-finding rate. To obtain such a time series, note that one would expect that the redesign of the CPS instrument would not affect measured unemployment duration in rotation groups 1 and 5, the "incoming rotation groups," because these workers are always asked their unemployment duration, but would reduce the measured short-term unemployment rate in the remaining six rotation groups.

To see this empirically, I use CPS micro data from January 1976 to March 2004 (www.nber.org/data/cps_basic.html) to measure short-term unemployment. In an average month from January 1976 to January 1994, short-term unemployment accounted for 41.6 percent of total unemployment in the full CPS and 41.7 percent in the incoming rotation groups, an insignificant difference. From February 1994 to March 2004, however, short-term unemployment accounted for 38.6 percent of unemployment in the full sample but 44.6 percent in the incoming rotation groups, an economically and statistically significant difference. Put differently, the short-term unemployment rate in the full CPS fell discontinuously between January and February 1994, while it remained roughly constant in the incoming rotation groups.

In this paper I use short-term unemployment from the full sample from January 1948 to January 1994 and then use only the incoming rotation groups in the later period. More precisely, I multiply the number of unemployed workers in the full CPS sample by the fraction of short-term unemployed among unemployed workers in the incoming rotation groups. ${ }^{14}$ This avoids any discontinuity associated with the redesign of the CPS. ${ }^{15}$

\footnotetext{
${ }^{13}$ The post-1994 methodology also prevents respondents from erroneously reporting short unemployment duration month after month.

${ }^{14}$ This approach circumvents another problem. From 1976 to 2004, the unemployment rate in the first rotation group averaged 0.4 percentage points more than in the full sample. See Solon (1986) for an analysis of rotation-group biases in the CPS.

${ }^{15}$ I have also tried multiplying the standard series for short-term unemployment by a constant, 1.1, after January 1994, which delivers very similar results.
} 
